\title{
Synthesis of Cosecant and Square Patterns for EMC applications
}

\author{
G. R. L. V. N. Srinivasa Raju ${ }^{1}$, Prof. G. S. N. Raju ${ }^{2}$ \\ ${ }^{I}$ Faculty in Department of Electronics \& Communication Engineering, Sri Vishnu Engineering College for \\ Women, Bhimavaram. Pin- 534202 \\ ${ }^{2}$ Department of Electronics \& Communication Engineering, Andhra University, Visakhapatnam, Andhra \\ Pradesh, India.
}

\begin{abstract}
Many researchers made an attempt on Beam shaping of antennas useful for different applications in surveillance and tracking radars. In the present work, synthesis of line source and linear antenna array with uniform current amplitudes and weight functions is discussed. An iterative sampling method approach is being considered for implementation. In an iterative method, original radiation pattern which is close to the desired radiation pattern is generated by a standard synthesis method and a series of correction patterns are applied to it by adding correction patterns until the convergence is achieved. The iterative method is implemented for both line source and linear array for generating cosecant and square radiation patterns and their results are compared. The patterns designed are found to exhibit minimum suitable levels and they are useful to instigate the problems of EMC.
\end{abstract}

Keywords: Line source; Radiation pattern; Sidelobe; Ripple; Desired pattern.

\section{Introduction}

Antennas are designed to produce desired patterns and they are optimized under a set of specified constraints. The constraints can be sidelobe level, Null-to-Null beamwidth, VSWR, and impedance etc. It is always possible to compute amplitude and phase excitations for a specified radiation pattern. Most often, only amplitude is computed without any phase function. The design uses a systematic method or combination of methods to arrive at an antenna configuration that produces a pattern that will match the actual radiation pattern as close as possible.

The radiation pattern synthesis can be applied to a continuous line source and a discrete linear array [2]. A Line source is considered to be a current distribution along a line of finite length. The amplitude distribution of a line source is a function of only one coordinate. A linear array is a group of elements arranged along a line with a finite spacing between the elements. The amplitude distributions of an antenna arrays is also discrete and the radiation pattern of these arrays are in the form of finite summation.

In the design of practical antenna systems the main task is to find out the antenna configuration, its geometrical dimensions and excitation to produce a pattern with narrow beam width, low side lobes and decaying minor lobes. The boundary conditions that must be taken into account in the design of antennas are Aperture size, Source complexity and Closeness of fit to the desired pattern [3].

An Iterative sampling method is an iterative procedure. It starts with any pattern, which is an approximation to the desired pattern and its corresponding current distribution. The original pattern can be from any standard design or possibly even an experimental pattern. The design chosen for the original pattern is Woodward Lawson method.

A pattern produced with a standard design like Woodward Lawson method is used in Iterative sampling method. In an iterative sampling method corrections are applied to the pattern obtained from a standard design to make the approximation pattern more nearly satisfy the specifications on the closeness fit. A correction pattern is derived by comparing the pattern produced from synthesis method with the desired pattern. This is the first iteration. If the resulting pattern is not satisfactory, additional corrections may be applied to the first iteration pattern. If the second iteration is also not yet satisfactory, further iterations are applied. Finally, this iteration process converges to give the desired pattern over the region where the corrections are applied. The change in the source current required to yield this pattern improvement is also easily calculated.

\subsection{Iterative Sampling method}

\section{Formulation}

Let $\mathrm{D}(\mathrm{u})=$ desired pattern, where $\mathrm{u}=\cos \theta$

$\theta=$ angle from the $\mathrm{z}$ axis along which the current distribution of aperture length $\mathrm{L}$ is disposed.

Iterative procedure begins with any pattern which is some approximation to $\mathrm{F}_{\mathrm{d}}(\mathrm{u})$ and its corresponding source current. This original pattern $\mathrm{F}^{(0)}(\mathrm{u})$ can be that of any standard design or possibly even an experimental pattern. A series of correction patterns is then added to the original pattern. If the resulting pattern, called the 
first-iteration pattern, is not satisfactory, further iterations may be applied [11]. For the $\mathrm{i}^{\text {th }}$ iteration, the total pattern correction is the sum of the correction patterns weighted by correction coefficients as follows

$$
\Delta \mathrm{R}^{(\mathrm{i})}(\mathrm{u})=\sum_{\mathrm{n}=-\mathrm{N}}^{\mathrm{N}} \mathrm{a}_{\mathrm{n}}^{(\mathrm{i})} \mathrm{G}\left(\mathrm{u}-\mathrm{u}_{\mathrm{n}}^{(\mathrm{i})}\right)
$$

Where $a_{n}^{(i)}$ is the correction coefficient and $G\left(u-u_{n}^{(i)}\right)$ is the correction pattern centred at and having a value of unity there. The number $\mathrm{N}$ is chosen such that the largest number of corrections $(2 \mathrm{~N}+1$ if odd and $2 \mathrm{~N}$ if even) of all the iterations is accommodated; for other iterations many of the $\mathrm{a}_{\mathrm{n}}^{(\mathrm{i})}$ coefficients will be zero. The resultant pattern after $\mathrm{K}$ iterations is the sum of the original pattern and all corrections:

$\mathrm{R}^{(\mathrm{k})}(\mathrm{u})=\mathrm{R}^{(0)}(\mathrm{u})+\sum_{\mathrm{i}=1}^{\mathrm{k}} \Delta \mathrm{R}^{(\mathrm{i})}(\mathrm{u})$

For a line source the correction pattern and correction current terms $\mathrm{g}_{\mathrm{nm}}{ }^{(\mathrm{i})}$ are related by

$$
G_{\text {ap }}(u)=\int_{-\frac{L_{\lambda}}{2}}^{\frac{L_{\lambda}}{2}} g_{n}^{(i)}(s) e^{(j 2 \pi u s)} d s
$$

where's' is the normalized aperture coordinate $\mathrm{z} / \mathrm{X}$ and $L_{\lambda}$ is the normalized aperture length $\mathrm{L} / \mathrm{h}$.

The $i^{\text {th }}$ iteration for the line source

$\Delta \mathrm{r}_{\mathrm{ap}}^{(\mathrm{i})}(\mathrm{s})=\sum_{\mathrm{n}=-\mathrm{N}}^{\mathrm{N}} \mathrm{a}_{\mathrm{n}}^{(\mathrm{i})} \mathrm{g}_{\mathrm{n}}^{(\mathrm{i})}(\mathrm{s})$

The total current is then the sum of the original and all correction currents and after $\mathrm{K}$ iterations for the line source.

$\mathrm{r}_{\mathrm{ap}}^{(\mathrm{i})}(\mathrm{s})=\mathrm{r}_{\mathrm{ap}}^{(0)}(\mathrm{s})+\sum_{\mathrm{i}=1}^{\mathrm{k}} \Delta \mathrm{r}_{\mathrm{ap}}^{(\mathrm{i})}(\mathrm{s})$

For line sources one of the simplest correction patterns is

$\mathrm{G}_{\mathrm{ap}}\left(\mathrm{u}-\mathrm{u}_{\mathrm{n}}^{(\mathrm{i})}\right)=\frac{\sin \left[\mathrm{L}_{\lambda}\left(\mathrm{u}-\mathrm{u}_{\mathrm{n}}^{(\mathrm{i})}\right) \pi\right]}{\mathrm{L}_{\lambda}\left(\mathrm{u}-\mathrm{u}_{\mathrm{n}}^{(\mathrm{i})}\right) \pi}$

These functions satisfy with $\Delta \mathrm{u}=1 / \mathrm{L}_{\lambda}$. Corresponding to this we have

$\mathrm{g}_{\mathrm{n}}^{(\mathrm{i})}(\mathrm{s})= \begin{cases}\left(\frac{1}{\mathrm{~L}_{\lambda}}\right) \mathrm{e}^{-\mathrm{j} 2 \pi \mathrm{u}_{\mathrm{n}}^{(\mathrm{i})} \mathrm{s}}|\mathrm{s}| \leq \mathrm{L}_{\lambda / 2} \\ 0 & \text { elsewhere }\end{cases}$

For an array the correction pattern and correction current terms $\mathrm{g}_{\mathrm{nm}}{ }^{(\mathrm{i})}$ are related by

$\mathrm{G}_{\mathrm{ar}}\left(\mathrm{u}-\mathrm{u}_{\mathrm{n}}^{\mathrm{i}}\right)=\sum_{\mathrm{m}=-\mathrm{M}}^{\mathrm{M}} \mathrm{g}_{\mathrm{nm}}^{\mathrm{i}} \mathrm{e}^{-\mathrm{j} 2 \pi \mathrm{us}} \mathrm{m}$

Where $\mathrm{s}_{\mathrm{m}}=\mathrm{z}_{\mathrm{m}} / \lambda$ gives normalized element positions spaced $\mathrm{d}_{\lambda}$

Number of elements $=\left\{\begin{array}{lr}2 \mathrm{M}+1 & \text { odd } \\ 2 \mathrm{M} & \text { even }\end{array}\right.$

For a linear array the $\mathrm{i}^{\text {th }}$ iteration total current correction is

$\Delta \mathrm{I}_{\mathrm{m}}^{(\mathrm{i})}=\sum_{\mathrm{n}=-\mathrm{N}}^{\mathrm{N}} \mathrm{a}_{\mathrm{n}}^{\mathrm{i}} \mathrm{g}_{\mathrm{nm}}^{(\mathrm{i})} \quad|\mathrm{m}| \leq \mathrm{M}$

After $\mathrm{i}^{\text {th }}$ iteration the total current which is some of the original and correction patterns is given by

$\mathrm{I}_{\mathrm{m}}^{\mathrm{k}}=\mathrm{I}_{\mathrm{m}}^{(0)}+\sum_{\mathrm{i}=1}^{\mathrm{k}} \Delta \mathrm{I}_{\mathrm{m}}^{(\mathrm{i})} \quad|\mathrm{m}| \leq \mathrm{M}$

The correction pattern for an array is obtained by

$$
\mathrm{G}_{\mathrm{ar}}\left(\mathrm{u}-\mathrm{u}_{\mathrm{n}}^{(\mathrm{i})}\right)=\frac{\sin \left[\pi \mathrm{d}_{\lambda}\left(\mathrm{u}-\mathrm{u}_{\mathrm{n}}^{(\mathrm{i})}\right) \mathrm{P}\right]}{\operatorname{P\operatorname {sin}}\left[\pi \mathrm{Ci}_{\lambda} \mathrm{d}\left(\mathrm{u}-\mathrm{u}_{\mathrm{n}}^{(\mathrm{i})}\right)\right]}
$$

For a given iteration, the corrections are limited to $2 \mathrm{~L}_{\lambda}+1$ [7]

$$
a_{n}^{(i)}=D\left(u_{n}^{(i)}\right)-R^{i-1}\left(u_{n}^{(i)}\right)
$$

A good choice of iterative sample points is the mean va.lue of the previous iterative sample points are

$$
\mathrm{u}_{\mathrm{n}}^{(\mathrm{i})}=\frac{\mathrm{u}_{\mathrm{n}}^{(\mathrm{i}-1)}+\mathrm{u}_{\mathrm{n}-1}^{(\mathrm{i}-1)}}{2}
$$

With successive iterations the number of iterative sample points is reduced as the pattern approaches the desired pattern to within acceptable limits, i.e., further corrections are applied over regions where the pattern error is still unacceptable.

The pattern improvement is found using several parameters.

SLL $=\frac{\text { highest side lobe level of }\left|F^{(k)}(\mathrm{u})\right|}{\text { maximum value of }\left|F_{\mathrm{d}}(\mathrm{u})\right|}$

Ripple in the main beam region

$\mathrm{V}=\max \left|\mathrm{D}(\mathrm{u})-\mathrm{R}^{(\mathrm{k})}(\mathrm{u})\right|$

Transition width

$\mathrm{W}=\left|\mathrm{U}_{0.9-} \mathrm{U}_{0.1}\right|$

$\xi=\int_{-1}^{1}\left|R(u)-R^{(k)}(u)\right|^{2} d u$

Supergain ratio 


$$
V=\frac{\int_{-\infty}^{\infty}\left|R_{a p}^{(k)}(\mathrm{u})\right|^{2} \mathrm{du}}{\int_{-1}^{1}\left|R_{\mathrm{ap}}^{(\mathrm{k})}(\mathrm{u})\right|^{2} \mathrm{du}}
$$

2.2 Desired patterns:

Cosecant pattern

$$
D(u)= \begin{cases}1.0, & 0 \leq u \leq 0.2 \\ \frac{0.2}{u} & 0.2 \leq u \leq 1.0 \\ 0, & \text { elsewhere }\end{cases}
$$

Sector pattern

$$
\mathrm{D}(\mathrm{u})= \begin{cases}1, & 0 \leq|\mathrm{u}| \leq 0.5 \\ 0, & \text { elsewhere }\end{cases}
$$

\section{Results}

The simulation of synthesis of line source and linear array is carried out using MATLAB software. Cosecant and sector radiation patterns (19)-(20) are generated for line source and linear array and the results are compared. The results of all the patterns are derived by applying correction patterns using (5)-(7) for line source and (9)-(11) for linear array with an iterative procedure. Initially the patterns are approximated with Woodward Lawson method and then Iterative procedure is applied. For a Cosecant pattern after four iterations convergence is achieved, whereas for a Sector pattern convergence is achieved after second iteration. The amplitude distributions of Cosecant pattern after each iteration is shown in figs. (1-4). The current distribution related to fourth iteration yielding convergence is shown in fig. 5. For a sector pattern the amplitude distributions and current distribution related to a converged pattern are shown in figs. (6-9).

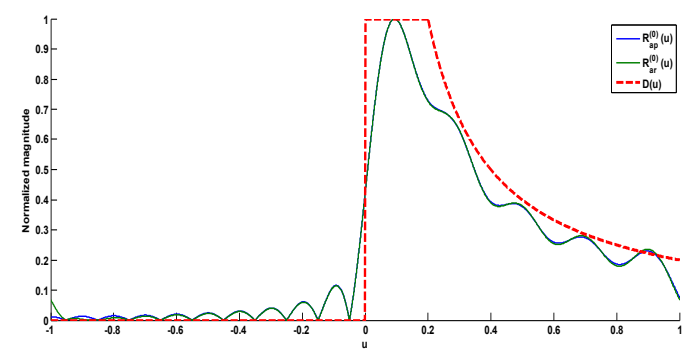

Fig. 1 Original cosecant pattern of ten wave length Line Source and Linear array $O f L=10 \lambda$ \& $N=20$ with Woodward Lawson method.

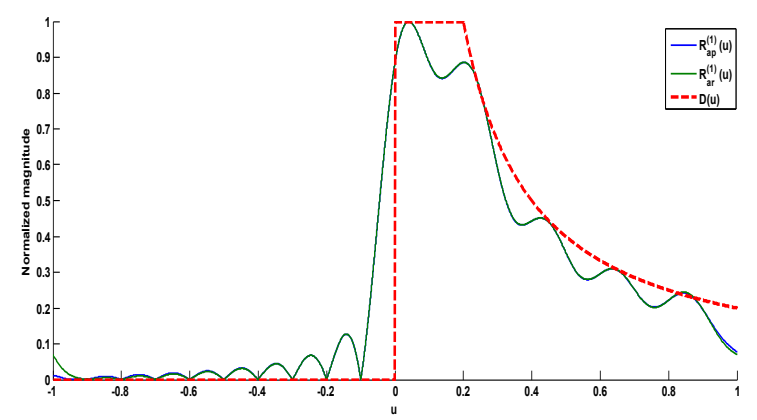

Fig. 2 Cosecant pattern of ten wave length Line Source and Linear array of $\mathrm{L}=10 \lambda \& \mathrm{~N}=20$ after first iteration.

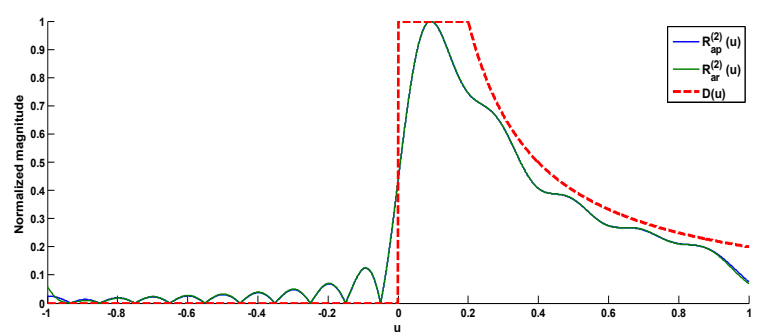

Fig. 3 Cosecant pattern of ten wave length Line Source and Linear array of $L=10 \lambda \& N=20$ after two iterations. 


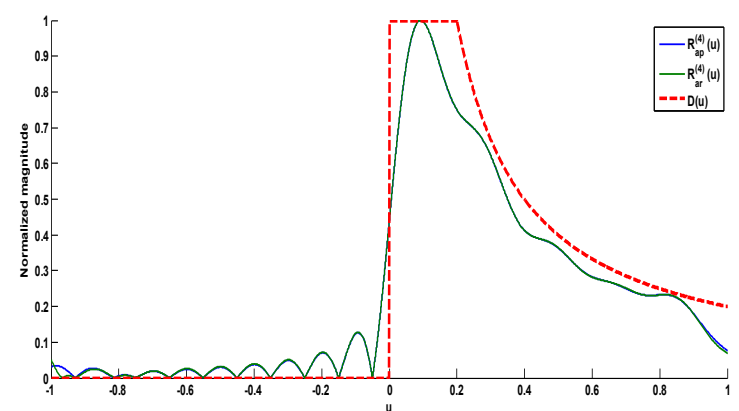

Fig. 4 Cosecant pattern of ten wave length Line Source and Linear array of $L=10 \lambda \& N=20$ after four iterations.

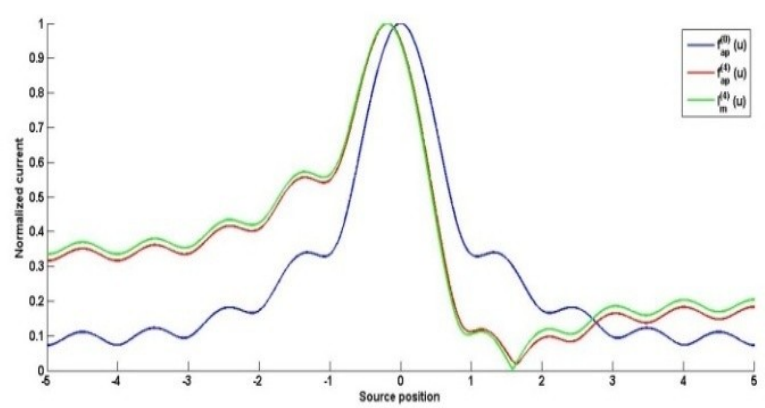

Fig. 5 Current distribution of cosecant pattern of ten wave length Line Source and Linear array of L=10 \& \& $\mathrm{N}=20$ after four iterations.

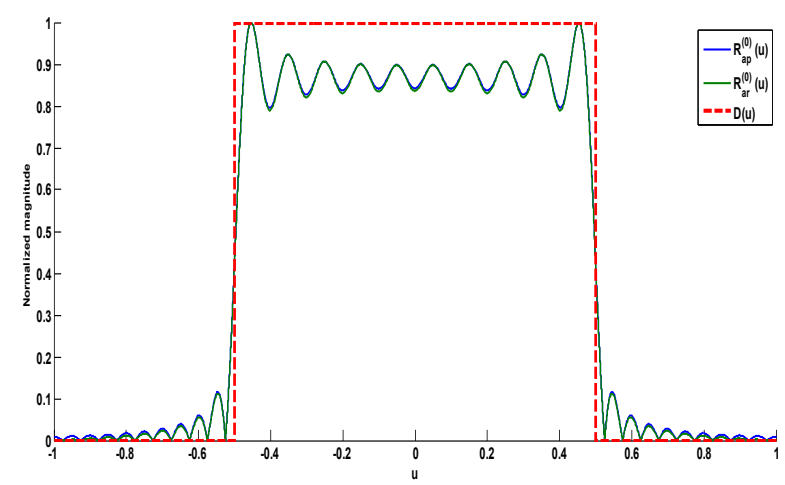

Fig. 6. Original sector pattern of twenty wave length Line Source and Linear array of $L=20 \lambda$ \& $N=40$ with Woodward method.

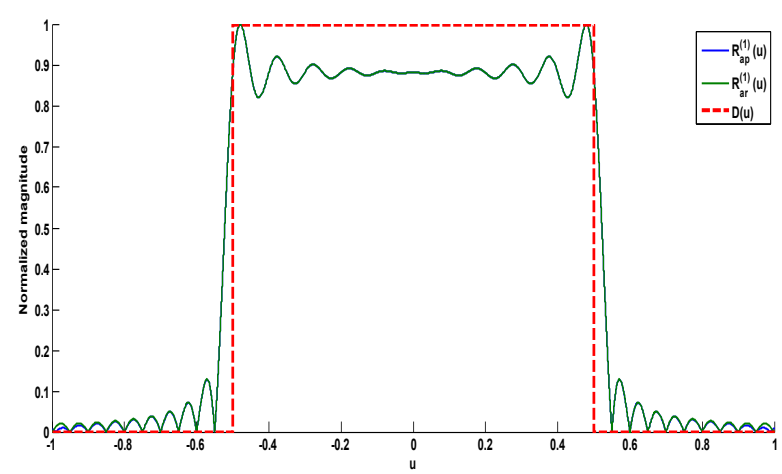

Fig. 7 Sector pattern of twenty wave length Line Source and Linear array of $L=20 \lambda$ \& $N=40$ after first iteration. 


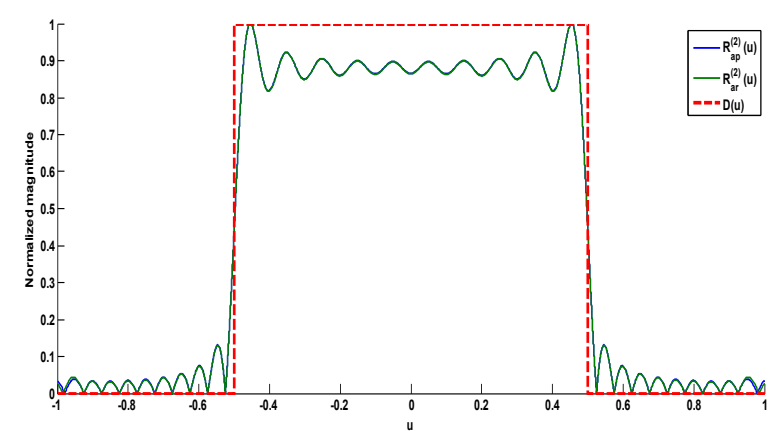

Fig. 8 Sector pattern of twenty wave length Line Source and Linear array of $L=20 \lambda$ \& $N=40$ after two iterations.

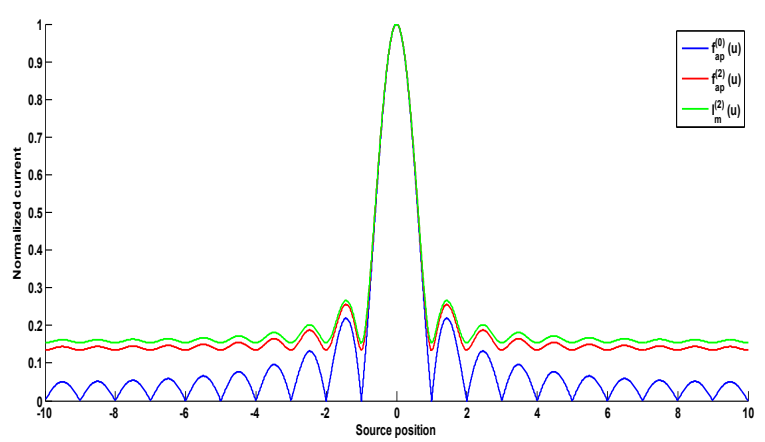

Fig. 9 Current distribution for sector pattern of twenty wave length Line Source and Linear array of $L=20 \lambda$ \& $\mathrm{N}=40$ after one iteration.

\section{Conclusions}

In this paper, studies on synthesis of cosecant and sector beams using iterative sampling method are made for line source and uniformly spaced linear array and their results are compared. It is found that the sidelobe level and ripple are decreased with successive iterations where as transition width and excitation current variation are increased when compared to Woodward Lawson method. When the results of line source and linear array are compared, it is found that the sidelobe levels of linear array are slightly reduced and error is slightly increased. It is observed that there is a tradeoff, between sidelobe level and transition width. The iterative sampling method introduced for shaped beam synthesis is not limited to only that type of pattern and it is useful an excellent to control sidelobe behavior.

\section{Refrences}

[1]. G.S.N.Raju, Antennas and Wave Propagation, Pearson Education, 2005.

[2]. Constantine A. Balanis, Antenna Theory, $2^{\text {nd }}$ ed. , New York: John wiley \& Sons, Inc., 1982.

[3]. W. 1. Stutzman and Gary A. Thiele, Antenna Theory and design, John wiley \& Sons, Inc., U.S.A. ch.10.

[4]. S.Silver, Microwave Antenna Theory and Design, vol. 12 (M.I.T Radiation Lab. Series). New York: McGraw-Hill, 1949, pp. 466467.

[5]. R. E. Collin and F. J. Zucker, Antenna Theory, pt. 1. New York: McGraw-Hill, 1969, chs.5,7.

[6]. R. F. Hyneman and R. M. Johnson, "A technique for the synthesis of shaped- beam radiation patterns with approximately equipercentage ripple,” IEEE Trans. Antennas Propagat., vol. AP-15, pp. 736-743, November 1967.

[7]. P. M. Woodward and J. D. Lawson, "The theoretical precision with which an arbitrary radiation-pattern may be obtained from a source of finite size," J. IEE(London), vol. 95, pt. III, pp. 363-370, September 1948.

[8]. T. T. Taylor, "Design of line-source antennas for narrow beam-width and low side lobes," IRE Trans. Antennas Propagat., vol . AP-3, pp. 16-28, January 1955.

[9]. D. R. Rhodes, "The optimum Line- source for the best mean-square approximation to a given radiation pattern ," IEEE Trans. Antennas Propagat., vol. AP-II, pp. 440-446, July 1963.

[10]. W. 1. Stutzman, "Evaluation of the mean squared error optimum line source patterns," IEEE Trans. Antennas Propagat.,vol. AP-18, pp. 808-809, NOVEMBER 1970.

[11]. W. 1. Stutzman, "Synthesis of Shaped-Beam Radiation Patterns Using the Iterative Sampling method," IEEE . Antennas Propagat., vol. AP-19, pp. 36-41, January 1971.

[12]. R. Ramana Reddy, G.S.N. Raju, et al., "Effect of length of line source on the overall radiation patterns," Proc. of Progress in Electromagnetics Research Symposium (PIERS-2007)," Prague, Chezc Republic, 27-30, Auguest 2007.

[13]. G. S. N. Raju et al., "Generation of Ramp Type of Radiation patterns from an array antennas," National Journal of EMC, Vol. 2, pp. 5-12, October 1995.

[14]. G. S. N. Raju et al., "Generation of Ramp patterns using amplitude control,” Proc. of FACT-2K, PP. 43-48, February 2000. 
[15]. G. S.N. Raju and Ajay Chackraborthy., "Synthesis of non linear phase function for the generation of CSC $^{2}$ patterns," IEMA Journal, pp. 37-38, May 1986.

[16]. Hans Steyskal, "Synthsis of antenna patterns with prescribed nulls," IEEE Transactions on Antennas and Propagation, Vol. AP- 30, No. 2, pp. 272-278, March 1982.

[17]. G. S.N. Raju and G. R. L.V. N. S. Raju.," Generation of shaped beam radiation patterns from a line source using iterative sampling method," International journal of Engineering Science and Technology," Vol, 5, Issue 8, pp. 1121-1128, August 2008.

[18]. W. L. Stutzman and E. L. Coffy, "Radiation pattern synthesis of planar antennas using the Iterative sampling method,"IEEE transactions on Antennas and Propagation, Vol. AP-23, No. 6, pp.764-768, November 1975.

[19]. Ryuing Sun, "Synthesis of shaped beam for base-station antennas in cellular mobile Communications, " Computer and information science, Vol. 3, No. 1, pp. 188-191, February 2010. 